\title{
In vivo quantification of the Achilles tendon moment arm Frances T Sheehan
}

Address: Physical Disabilities Branch, National Institutes of Health, Bethesda, MD, USA

Email: Frances T Sheehan - fsheehan@cc.nih.gov

from Ist Congress of the International Foot \& Ankle Biomechanics (i-FAB) community

Bologna, Italy. 4-6 September 2008

Published: 26 September 2008

Journal of Foot and Ankle Research 2008, I(SuppI I):P2 doi:I0.1 I86/I757-I I46-I-SI-P2

This abstract is available from: http://www.jfootankleres.com/content/I/SI/P2

(c) 2008 Sheehan; licensee BioMed Central Ltd.

\section{Introduction}

The Achilles' tendon moment arm (ATma) is a critical quantity in that it defines the triceps surea's ability to generate a moment on the calcaneus, which is then transferred to the foot. In the past this measure has been primarily acquired statistically, in $2 \mathrm{D}$, without muscle activation, and in small populations. Thus, the primary purpose of this study was to establish the first in vivo threedimensional measures of the ATma, measured non-invasively and in vivo during dynamic activity in a large normative population $(n=19)$ using a dynamic MRI technique. The ATma was defined as the shortest distance between the finite helical axis (FHA) of the calcaneal-tibial joint and the AT line of action.

\section{Methods}

Nineteen healthy subjects $(25.5 \pm 3.7$ years, $70.1 \pm 13.1$ $\mathrm{kg}, 174.3 \pm 7.8 \mathrm{~cm}, 6 \mathrm{~F} / 14 \mathrm{M}$ ) participated in this IRB approved study. Subjects were placed supine in a $1.5 \mathrm{~T} \mathrm{MR}$ imager (LX; GE Medical Systems, Milwaukee, WI, USA) after obtaining informed consent. An MRI-compatible device was used to apply a plantarflexion (PF) load. This device allowed natural 3D motion at both joints of the hindfoot. While subjects cyclically plantarflexed and dorsiflexed their ankle at 35 cycles/min fast-PC MR images (anatomic and $\mathrm{x}, \mathrm{y}$, and $\mathrm{z}$ velocity images, temporal resolution $=72 \mathrm{~ms}$, imaging time $=2: 48$ ) were collected [1] The sagittal-oblique imaging plane contained the soleus musculotendon junction, tibia, talus and calcaneus. The 3D time dependent tibial, talar and calcaneal attitudes along with the soleus displacement were derived by integrating the velocity data. From these data the FHAs and ATmas were determined. Averages are presented for PF only and for ranges represented by 3 or more subjects The range of motion was self-selected, thus not all subjects are represented at all ankle angles.

\section{Results}

A slight decrease in the ma was seen in PF from $-2^{\circ}$ DF to $39^{\circ} \mathrm{PF}\left(0^{\circ}=\right.$ anatomically neutral $)$. Women tended to have a slightly smaller ATma and stature, but a correlation between ATma and height was not found. Figure 1.

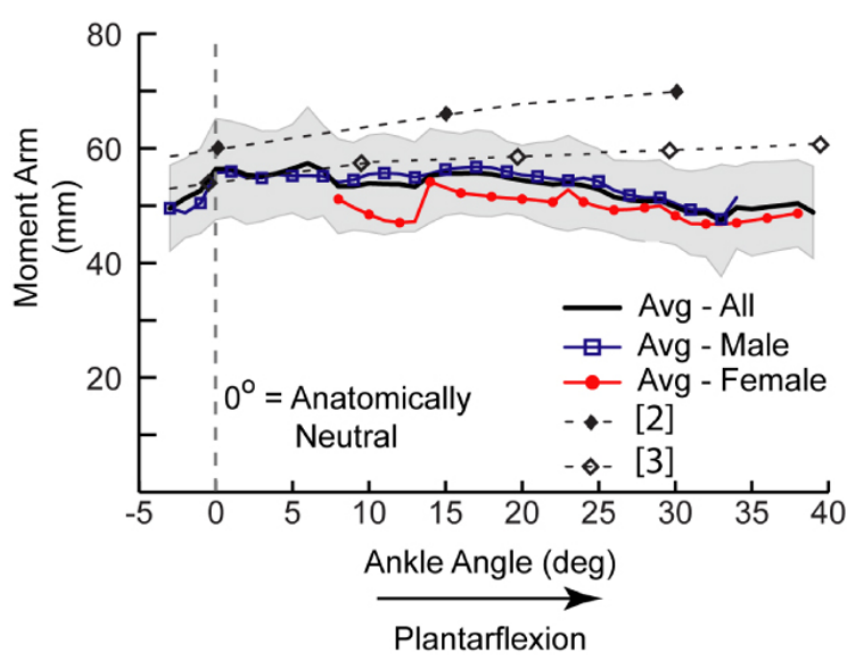

Figure I

Achilles' tendon MA. Grey shading $= \pm$ I SD for the average of all subjects. The SD for female and male groups is similar to the SD for all subjects. Black dashed lines indicate data from past studies $[2,3]$. 


\section{Conclusion}

This study is the first to quantify the ATma non-invasively and in vivo during loaded $\mathrm{PF}$, using a population size twice that of most past studies. The slight decrease in ATma during PF was due primarily to posterior displacement of the calcaneal-tibial FHA, but some of this change could also be attributed to the 3D change in FHA orientation. These data are similar in value to past studies, but the steady increase in value during PF was not found $[2,3]$. This is likely due to the 3D nature of this experiment and that the moment arm was calculated directly from the FHA. Thus, the assumptions required for the center of rotation and tendon excursion methods did not limit the current experiment. The small number of female subjects makes comparing the two groups difficult, but the smaller ATma was expected due to the average height difference $(161.3 \pm 1.8 \mathrm{~mm}$ vs. $176.0 \pm 3.4 \mathrm{~mm})$. Since a correlation between height and ATma could not be established, normalization was not used.

\section{References}

I. Sheehan FT, et al:: Foot Ankle Int 2007, 28(3):323-3.

2. Maganaris SN, et al.: Eur J Appl Physiol 2004, 9 I:I30-9.

3. Rugg SG: J Biomech 1990, 23(5):495-50I.
Publish with Biomed Central and every scientist can read your work free of charge

"BioMed Central will be the most significant development for disseminating the results of biomedical research in our lifetime. " Sir Paul Nurse, Cancer Research UK

Your research papers will be:

- available free of charge to the entire biomedical community

- peer reviewed and published immediately upon acceptance

- cited in PubMed and archived on PubMed Central

- yours - you keep the copyright

Submit your manuscript here:

http://www.biomedcentral.com/info/publishing_adv.asp 